\section{The Habits and Distribution of Scutigera in Indıa.}

BEYOND the bare fact of its occurrence, but little else seems to have been recorded concerning either the habits or distribution of this remarkable myriapod in India. During the last three years I have come across it on many occasions, and it proves to be very widely distributed in the United Provinces. It occurs from a few hundred feet above sea-level in the plains, at Allahabad, up to nearly is,ooo feet in the Himalayas, having thus a considerable vertical range. I have found it plentiful at Bhowali, among the Himalayan foot-hills of Kumaon, at 5700 feet, and at many other localities in the same district. It occurs at Dhakuri and Dhwali at an elevation of 9000 feet, and also at Phurkia at about ro,300 feetabout five miles below the Pindari glacier. In the neighbouring district of Garhwal I have met with it this year under stones between Badrinath and the village of Mana, situated at the entrance of the pass of the same name into Tibet. The elevation was approximately ro,800 feet, or possibly a little more. How many species are included within this area of distribution I am unable to say, as the Indian forms are at present being worked out by Prof. Silvestri.

Scutigera exhibits a strong dislike to expose itself to daylight and sunshine, and lurks during the daytime in dark places. The commonest situation for finding it is under matting covering the floors of bungalows, or on walls in dark corners, or under stones, \&c., out of doors. Sinclair, in vol. v. of the "Cambridge Natural History," states that in Malta Scutigera darts about in the hot sunshine after its prey. In India, so far as my experience goes, it is a nocturnal animal. It is difficult to secure perfect examples, for Scutigera never seems loth to part with one or more of its extremely long and fragile limbs, which are dismembered with extreme readiness. After separation from the body the legs exhibit active muscular contractions for about twenty or thirty seconds. One of its chief enemies in the plains seem to be scorpions, which inhabit very much the same situations. On one occasion a large Buthus was observed to seize a Scutigera by several of its legs with one of its pedipalps. The Scutigera departed in great haste, and made good its escape, leaving several legs behind in the possession of the scorpion. From this occurrence one is led to suggest that the extreme length of the legs of Scutigera may perhaps be an adaptive modification for defensive purposes. When an animal is encompassed by such an armature of appendages it makes it difficult for an enemy to seize it by a more vital part of the body.

From watching the living animal, there seems no doubt that the extremely long and antenna-like hind pair of legs function as sense-organs. Individuals in captivity kept these appendages frequently uplifted and on the move after the same manner as antennæ. A large spider was placed in a vessel along with a Scutigera, and the latter manifested great alarm. The long posterior appendages were kept in constant agitation, apparently to guard against a rear attack, while the antennæ were behaving in the same manner at the opposite end of the body.

$$
\text { A. D. Imms. }
$$

Biological Laboratory, Muir College, University of Allahabad, September 5 .

\section{Fire Tests with Textiles.}

I sHaLl be glad if you will insert the following letter in reference to fire test with textiles, as the conclusions at which $I$ have arrived, after repeated experiments, are so different from those reached by the British Fire Prevention Committee that I feel I cannot allow the assertions of that committee to pass unchallenged. I have over and over again shown publicly and privately, including a demonstration to the members of the Home Office Committee referred to below, that "Non-flam" flannelette is only non-inflammable if it is washed in a certain way. If washed in the manner usually employed by the ordinary housewife, i.e. washed with soap and water, and finally wrung out of clear water until all trace of soap has gone, it burns as readily as ordinary cheap flannelette. This fact was testified to by many witnesses besides myself before the Home Office Committee. The manufacturers of "Non-flam" acknowledge. this in a letter to me (a letter which was added as a footnote to my evidence before the Departmental Committee on Coroner's Law, second report, p. 42), from which the following are extracts :- " If a piece of Non-flam is washed ... with plenty of soap to form a good lather, and then rinsed in water, but not beyond the point at which the water on wringing runs a little milky, showing that a little soapy water still remains in the cloth, it will be found to have lost scarcely any of its fire-proof qualities even after repeated washings.... You may perhaps ask why we have not issued instructions as to the method of washing to be adopted with Non-flam. . . . It has never been done for two reasons. One is that to issue such instructions would create suspicion. . . The other reason is that, upon inquiry, we are satisfied that ninety-nine times out of a hundred the method which is followed in the domestic wash could hardly be improved upon... . The clothes, after washing, are seldom, if ever, rinsed until no soap is left in them." My contention is that this method of washing is not the one employed by the ordinary woman who washes at home. My school nurse made inquiries for me of a dozen mothers as to their method of washing their children's flannelette garments, and, without exception, they all said they finally wrung out of fresh water to get rid of all traces of soap. (The reason for this is, I believe, that if any soap is left in it makes the clothes nasty and sticky.)

I am confident that the I400 lives annually lost by burning and scalding in this country will only be substantially diminished when fire-guards are compulsory. Eighty-five per cent. of these deaths were proved to be due to the want of a guard. Section ${ }_{15}$ of the Children Act, excellent as it is, needs strengthening. It only renders it a penal offence if a child is burnt to death or seriously injured owing to the want of a fire-guard. It does not compel a parent to take reasonable precautions, by the provision of a guard, to prevent this burning.

I shall be most interested to see what conclusions are arrived at by Mr. Gladstone's committee after having heard the evidence of the various witnesses. The final report may be expected shortly.

83 Church Road, Hove, September 28.

LEONARD PARRY.

\section{Customs at Holy Wells.}

IT has been suggested that the following information is of sufficient interest to justify insertion in NATURE.

Some of your readers doubtless know the Well of St. Cubert, near Crantock, Newquay, and have read the guide-book description of the miraculous cures of infants which used to take place there in old times.

The book on ancient and holy wells in Cornwall, by $\mathrm{Mr}$. Quiller-Couch, gives a full account of the ceremonies which must be observed, and Sir Norman Lockyer quotes them in the chapter on holy wells in "Stonehenge and other Stone Circles."

These authorities seem, however, to be unaware that the help of St. Cubert was sought as late as the latter half of the nineteenth century. When we were at Newquay in 1886 , my parents' man-servant, a native of Mawgan, near Newquay, told the other servants that he as a delicate infant had been passed through the hole in the rock of St. Cubert's Well " for luck."

Whether all the proper ceremonies had been observed I cannot say. The servant must have been about eighteen years old in 1886 , and he was alive and well in 1898 , since which time we have lost sight of him.

\section{Littlewood, Weybridge, September 27.}

Zorah Godden.

\section{A Meteorological Phenomenon.}

ON Monday, September 26, travelling between Etaples and Breteuil, Chemins de Fer du Nord, en route to Paris, my family and myself and a friend (five in all) observed the following meteorological phenomenon.

The sun was hidden, but traceable, behind a white mist

NO. 2 I 36 , VOL. 84$]$ 